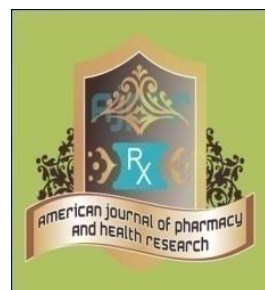

Research Article
AMERICAN JOURNAL OF PHARMACY AND HEALTH RESEARCH

www.ajphr.com

2020, Volume 8, Issue 6

ISSN: 2321-3647(online)

\title{
Effect of Fentanyl versus Ketamine Pre-anesthetic Propofol Injection Reducing Pain among General Anesthesia
}

\author{
Safa Bakr Karim* \\ Technical College of Health, Sulaimani Polytechnic University, Kurdistan Region, Iraq.
}

\begin{abstract}
Propofol is commonly used intravenous anesthesia induction drug but it causes ache upon use. Many methods with different results have been suggested to prevent this pain. The current research was concluded in order to investigate the impact of fentanyl in reducing the ache on giving intravenous propofol. This study is randomized controlled clinical trial lasting from June 2019 to November 2019 during which 107 consenting (ASA1 and ASA2) patients were prepared for elective operation with general anesthesia. They randomly split to three subgroups, A cannula (size20) used in the dorsum hand veins, standard monitor was established patients received either $2 \mathrm{~mL}(40 \mathrm{mg}$ ) of fentanyl or $2 \mathrm{~mL}(20 \mathrm{mg})$ of ketamine and $2 \mathrm{~mL}$ of normal saline $1 \mathrm{~min}$ before injection 2.5 milligram per kilogram propofol. Ache severity observed by using four number pain scale , zero $=$ none, one $=$ mild pain, two $=$ moderate pain and three $=$ intense pain. There were no variations between the study groups regarding ASA status, Sex, and age. The incidence of ache when injecting propofol were observed in the normal saline group was $86.5 \%$ and it was more than ketamine group $0 \%$ and fentanyl group $20 \%$ ( $\mathrm{p}=0.0002)$. In the normal saline pretreatment group $8.1 \%$ of the patient experienced severe pain, compared with $0 \%$ in the fentanyl and ketamine. It can be concluded that intravenous ketamine and fentanyl were equally effective in preventing ache during propofol injection.
\end{abstract}

Keywords: Propofol, pain, Fentanyl, anesthesia, surgery.

*Corresponding Author Email: safabakrbakr@gmail.com

Received 10 May 2020, Accepted 22 May 2020

Please cite this article as: Karim SB et al., Effect of Fentanyl versus Ketamine Pre-anesthetic Propofol Injection Reducing Pain among General Anesthesia. American Journal of Pharmacy \& Health Research 2020. 


\section{INTRODUCTION}

Propofol is the most frequently used intravenous anesthetic agent for anesthesia induction and maintenance, providing a smoother induction and quicker recovery compared to all other drugs such as thiopental ${ }^{1}$.

Many investigative and therapeutic medical procedures are painful, uncomfortable and/or otherwise distressing to the patient. The International Association for the Study of Pain (IASP) defines pain as "an unpleasant sensory and emotional experience associated with actual or potential tissue damage, or described in terms of such damage." 2

Whilst superficial diagnostic or surgical interventions may be performed with local anesthesia alone, complete regional anesthesia is often not possible and/or undesirable for many procedures. Some procedures, such as muscle biopsy by needle, specifically require that local anesthesia not be used beyond the skin. Many procedures may be performed with spinal anesthesia or individual limb anesthesia (nerve or Bier's block), but the placement of regional anesthesia is not without risk and often requires a recovery time longer than that for PSA. ${ }^{3}$

Pain is believed to be caused by direct stimulation of venous nociceptive receptors after injection of propofol, the nerve impulse being transferred by myelinated A delta fibers 4 .

The propofol lipid solvent activates the kallikrein kinin plasma system that generates bradykinin that changes the local vein injected. This peripheral vein alteration can improve the contact between the aqueous phase propofol and the free nerve endings of the vessel, leading to propofol aggravation, caused pain ${ }^{5}$.

Remifentanil and fentanyl are potent synthetic $\mu$-opioidagonists. Both drugs are administered to achieve intra-operative analgesia. Fentanyl has been widely investigated inveterinary anesthesia for many years. Fentanyl is metabolizedmainly in the liver, and its half-life is 2 to $3 \mathrm{~h}^{6}$.

After prolonged infusions, its side effects continue because of its cumulative effect 2,7,11. Its ultrashort action, rapid control of the depth of anesthesia, and lack of dependence on organ functions for breakdown and clearance make remifentanil more advantageous than fentanyl. Remifentanil does not accumulate in the body even after prolonged infusion, and its terminal half-life has been reported to be less than 6 minutes ${ }^{7}$.

The dose of fentanyl chosen for the combination was approximately a quarter of its ED as described in a previous study ${ }^{8}$.

The drugs were injected in a constant volume $(15 \mathrm{ml})$ over $15-20 \mathrm{~s}$. The combination drugs were administered separately; fentanyl being given 1 min before propofol and the end-point (no response to verbal command) was evaluated 2 min after the first drug. In measuring the dose- 
response of propofol alone, saline was injected initially instead of fentanyl; in the case of fentanyl alone, Intra-lipid 10\% was used instead of propofol. These two solutions were also added to the respective active drugs to standardize the injected volume $(15 \mathrm{ml})$. The drugs were labeled 'first' and 'second' so that the anesthetist was unaware of the doses ${ }^{9}$.

Ketamine may be given by multiple rote of administration including intravenous, oral, subcutaneous, intranasal, transdermal, but fentanyl should be administrated intravenously ${ }^{10}$.

\section{MATERIALS AND METHOD}

This is a normal saline-controlled randomized study that conducted at the anesthesia department in Sulaimani Teaching Hospital on patients undergoing general anesthesia for elective general surgery, between May 2019 and November 2019 after gaining local ethical committee acceptance. 107 consented patients with age range from twenty to sixty years old and ASA classification 1 and 2, patients randomly divided into three groups;

- $\quad \mathrm{N}$ : 37 patients took $2 \mathrm{ml} 0.9 \%$ sodium chloride

- F: 35 patients took $2 \mathrm{ml}(40 \mathrm{mg})$ of Fentanyl

- $\mathrm{K}: 35$ patients took $2 \mathrm{ml}(20 \mathrm{mg})$ Ketamine

Exclusion criteria were patient with severe respiratory, cardiovascular, cardiac conduction defect, neurological or renal disease (ASA III, IV), patient with difficulty in communication, hemodynamically unstable patient, mallampatic class (III, IV), patient had allergy to the study medications, analgesic drug or any sedative consumption in the preoperative period and patient with difficult cannulation.

All patients were managed with an intravenous cannula (size 20) inserted on the dorsum of the patient hand, standard monitoring like electrocardiogram, temperature, blood pressure (noninvasive), and pulse oximeter was established. Research drug was given 1minute from giving propofol (2.5mg/kilogram), the propofol injected over15 seconds, the ache level was evaluated and recorded, using four number rate scale, a score zero to three represents None $(0)$, mild pain (1), moderate pain (2) and sever pain (3). Patients were questioned about the pain presence on injecting propofol their answers, facial responses, tears, hand withdrawal and all that recorded.

- If it was negative answer to the questions equal to none.

- If patient answered yes to pain on question and there were no other signs (behavioral) this equal to mild.

- If patient report pain spontaneously without asking or had behavioral signs this equal to moderate. 
- If patient had strong vocal answer or his answer associated with grimacing of the face, tears or arm withdrawing this equal to sever

Tracheal intubation was facilitated with injection of atracurium (non- depolarizing neuromuscular blocking agent); fentanyl and isoflurane were used for maintenance. Anesthesia was maintained as per surgical requirement.

Statistical Package for the Social Sciences version 22.0 where used to analyze the Data, Also, Analysis of variance test, Chi-square $\left(\chi^{2}\right)$ test was used to test for significance of associations between the predictor and outcome variables in the categorical variables to find an outcome related to health issues. T-test used for comparison of the data. P-value of $<0.05$ was considered as statistically significant cutoff.

\section{RESULTS AND DISCUSSION}

107 patients involve in this research, in comparing patients age, sex and ASA physical status we found no significant differences between study groups (Table 1).

Table 1: Comparison between Ages, gender and ASA physical status in study groups.

\begin{tabular}{lllll}
\hline Variable & $\begin{array}{l}\text { Ketamine } \\
(\mathbf{N}=35)\end{array}$ & $\begin{array}{l}\text { Fentanyl } \\
(\mathbf{N = 3 5})\end{array}$ & $\begin{array}{l}\text { Normal saline } \\
(\mathbf{N}=37)\end{array}$ & p-value \\
\hline Age(year) & $35.46 \pm 11.92$ & $40.03 \pm 10.84$ & $39.97 \pm 9.66$ & 0.1 \\
Mean \pm SD & & & & \\
Gender (M:F) & $4 / 31$ & $8 / 27$ & $7 / 30$ & 0.4 \\
ASA (I:II) & $31 / 4$ & $21 / 14$ & $24 / 13$ & 0.084 \\
\hline
\end{tabular}

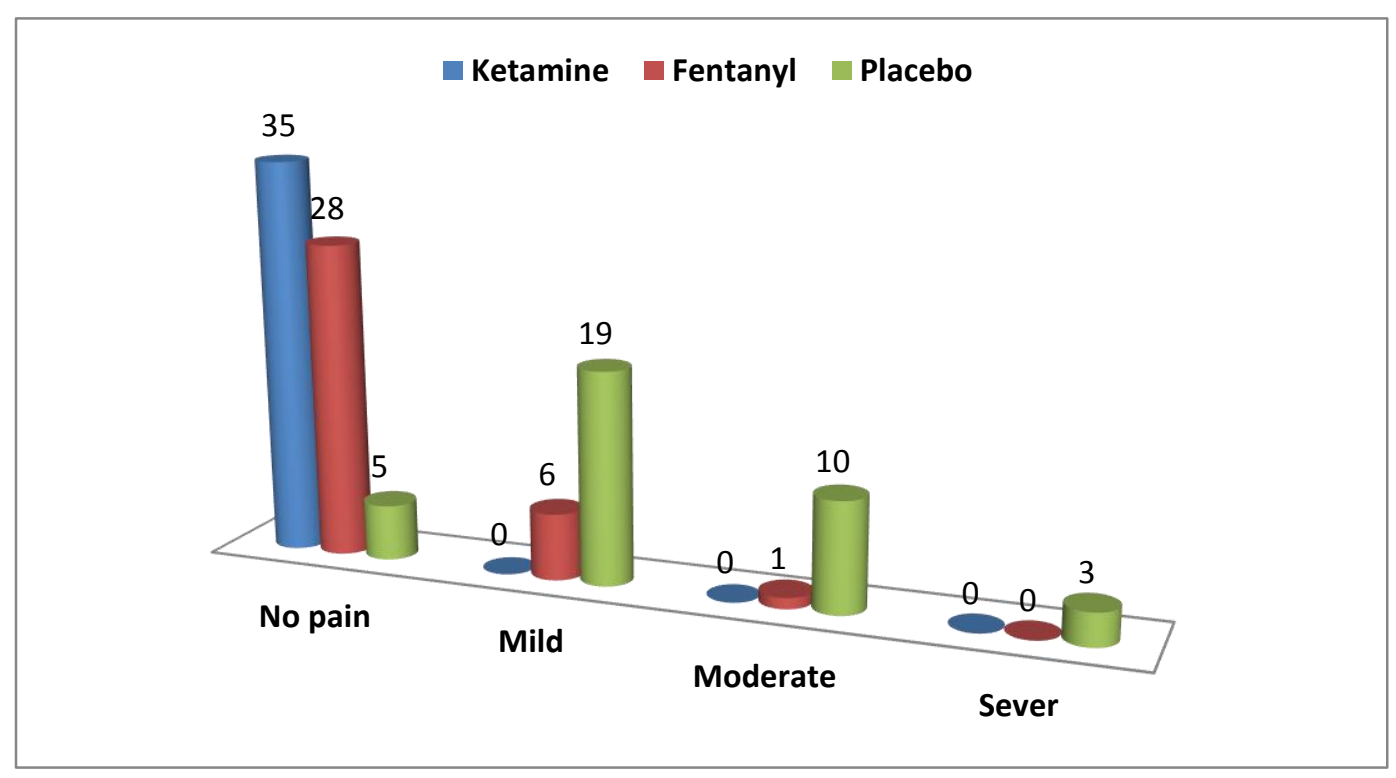

Figure 1: Differences in pain score between study groups.

While comparing the fentanyl group to the normal saline group, we found that there was significant difference between the two groups and the overall patients number having pain (mild, moderate, sever) was significantly less in fentanyl group. (Table 2, Figure 1) 
Table 2: Comparison of pain score, regarding of fentanyl and normal saline

\begin{tabular}{llll}
\hline Pain Score & $\begin{array}{l}\text { Fentanyl } \\
\text { N }(\%)\end{array}$ & $\begin{array}{l}\text { Normal saline } \\
\text { N }(\%)\end{array}$ & p-value \\
\hline No pain & $28(80 \%)$ & $5(13.5 \%)$ & 0.003 \\
Mild & $6(17.1 \%)$ & $19(51.4 \%)$ & 0.013 \\
Moderate & $1(2.9 \%)$ & $10(27.0 \%)$ & 0.009 \\
Sever & $0(0 \%)$ & $3(8.1 \%)$ & 0.092 \\
No pain: Pain & $28 / 7$ & $5 / 32$ & 0.0002 \\
\hline
\end{tabular}

In comparing the ketamine group to the normal saline group, we found that there were differences between those groups and it was statically significant and the overall patients number having pain (mild, moderate, sever) was significantly less in ketamine group. (Table 3, Figure 1)

Table 3: Comparison of pain score, regarding of ketamine and normal saline

\begin{tabular}{llll}
\hline Pain Score & $\begin{array}{l}\text { Ketamine } \\
\mathbf{N}(\%)\end{array}$ & $\begin{array}{l}\text { Normal saline } \\
\mathbf{N}(\%)\end{array}$ & p-value \\
\hline No pain & $35(100 \%)$ & $5(13.5 \%)$ & 0.009 \\
Mild & $0(0 \%)$ & $19(51.4 \%)$ & 0.002 \\
Moderate & $0(0 \%)$ & $10(27.0 \%)$ & 0.002 \\
Sever & $0(0 \%)$ & $3(8.1 \%)$ & 0.092 \\
No pain: Pain & $35 / 0$ & $5 / 32$ & 0.0002 \\
\hline
\end{tabular}

When comparing the ketamine group to the fentanyl group, we found that there were differences between the groups and those differences were significant in mild ache but in overall number of patients having pain to no pain was significantly less in ketamine group. (Table 4, Figure 1)

Table 4: Comparison of pain score, regarding of ketamine and fentanyl.

\begin{tabular}{llll}
\hline Pain Score & $\begin{array}{l}\text { Ketamine } \\
\text { N }(\%)\end{array}$ & $\begin{array}{l}\text { Fentanyl } \\
\mathbf{N}(\%)\end{array}$ & p-value \\
\hline No pain & $35(100 \%)$ & $28(80 \%)$ & 0.4 \\
Mild & $0(0 \%)$ & $6(17.1 \%)$ & 0.01 \\
Moderate & $0(0 \%)$ & $1(2.9 \%)$ & 0.31 \\
Sever & $0(0 \%)$ & $0(0 \%)$ & None \\
No pain: Pain & $35 / 0$ & $28 / 7$ & 0.006 \\
\hline
\end{tabular}

\section{DISCUSSION}

This use of propofol as intravenous anesthetic due to the high quality of anesthesia and fast recovery agent has risen quickly ${ }^{9}$. The injection pain caused by Propofol is linked to the quantity of free propofol in the aqueous stage. The free propofol contact with free nerve ending of vessels activates the plasma kinin-kallikrein system, which release pain mediators locally. Pain caused by propofol injection can be immediate or delayed; instant pain is probable due to direct irritant impact whereas delayed pain is probable due to indirect impact through the kinine cascade ${ }^{11}$. 
It is extremely desirable to avoid pain with propofol injection; many techniques have been used to decrease the incidence of pain with variable outcomes on propofol injection ${ }^{1}$.

Our randomized, focused on showing the efficacy of different medicines. Fentanyl and ketamine pretreatments were contrasted with placebo organizations to reduce the incidence and severity of propofol pain. Propofol injection without any medicine (placebo group) suffered pain in most of patients, some of them complaining of strong pain. But the impact of pain via pretreatment with fentanyl and ketamine decreases and no patient is having severe pain with ketamine and fentanyl. Thus, both ketamine and fentanyl pretreatment decreased incidence of pain on propofol injection and this was statistically significant. But Incidence of pain significantly less in the ketamine groups. This agrees with the following studies:

Saadawi Ertok et al, after they conducted a study on 125 patients for evaluation of efficacy ketamine, fentanyl, meperidine, thiopental compared to placebo to minimize propofol injection pain. They reported that the incidence of pain in all treatment groups was considerably smaller than in placebo. However, pretreatment with ketamine was found to be the most efficient in attenuating propofol-related pain ${ }^{12}$.

This agrees with Zahedi $\mathrm{H}$ et al, studied 500 patients compared ketamine; fentanyl to placebo groups in the Preventing propofol pain injection they recorded considerably reduced pain incidence and intensity in all study groups than the treatment group. And ketamine 100 microgram $/ \mathrm{kg}$ group had the incidence of pain is considerably smaller relative to fentanyl group injection pain ${ }^{10}$

Seung -WooKoo, sun jun cho et al, studied 240 patients and compared fentanyl, ketamine 3 different dose to placebo group, the results showed that a dose of ketamine $100 \mathrm{mcg} / \mathrm{kg}$ the incidence of propofol induced pain relative to fentanyl and placebo can be reduced ${ }^{13}$.

Bano F, Zafar S et al, studied 100 patients. They received $0.5 \mathrm{mg} / \mathrm{kg}$ ketamine in volume $2 \mathrm{ml}$ and $2 \mathrm{ml}$ of fentanyl, the incidence of propofol pain in the ketamine group was smaller but remained statistically small and this differs from our study because they injected $25 \%$ of the calculated propofol dose within 15 second and performed measurement while we injected the whole dose then performed measurement ${ }^{14}$.

While in previous study mentioned that 250 patients receiving remifentanil, fentanyl, ketamine, metoclopramide compared to placebo fentanyl or metoclopramide pretreatment decreased the incidence and severity of propofol caused pain fairly and substantially compared to pretreatment with ketamine and remifentanil. Although they agree with our study that fentanyl significantly 
reduces pain compared to placebo but disagree with our study in that ketamine is better than fentanyl probably because we used a higher dose of ketamine than this study ${ }^{11}$.

Vida Ayatollahin et al, studied 140 patients receiving ephedrine, ketamine, fentanyl compared to placebo, they found that ketamine has the best results between the drugs but it was not statistically significant this because they used a lower dose than the dose we used ${ }^{15}$.

Leena Jalota, Vicki Kalira, et al analyzed from 177 randomized controlled trials totaling 25260 adults. The general risk of propofol injection pain alone was approximately $60 \%$. Statistically, they calculated that the two most effective procedures to decrease pain in the injection of propofol were the use of the antecubital vein or pretreatment with fentanyl in combination with venous occlusion when the hand vein was selected on the premise of autonomous efficacy ${ }^{16}$.

In our study dose of fentanyl was (40mg) and most of the Patients had no propofol injection pain that was statistically important in comparison with placebo organizations. Because fentanyl has a local anesthetic impact or an inhibitory impact on the enzyme cascade that result in kinin release ${ }^{4}$. The result of the following studies supported the findings of our study.

Shreyasi Ray et al, studied 63 patients, compared efficacies of fentanyl $40 \mathrm{mg}$ with fentanyl pretreatment to reduce propofol injection pain, the result shown that fentanyl and fentanyl effectively reduce propofol injection pain compared to ordinary placebo saline ${ }^{5}$.

Nathanson, Michael $\mathrm{H}$ et al, compared alfentanil 1mg, fentanyl 40mg to placebo group to reduce pain during propofol injection; the result showed that both fentanyl and alfentanil the incidence of pain was considerably smaller than the placebo group ${ }^{17}$.

Pang WW, wang PY et al, researched 105 patients randomly assigned to receive tramadol, fentanyl $60 \mathrm{mg}$ or normal saline as a pretreatment for pain reduction with propofol injection. The results showed that both tramadol and fentanyl considerably decreased the incidence and intensity of propofol injection pain relative to normal saline ${ }^{18}$. Although this study results agree with our study but still they used a much higher dose of fentanyl than our dose.

Another study on 368 females, were allocated to one of four groups to received propofol mixed with different dose of fentanyl $(5 \mathrm{mg}, 10 \mathrm{mg}, 20 \mathrm{mg})$ compared to placebo, the result was shown that fentanyl $20 \mathrm{mg}$ Reduces the incidence and severity of pain in propofol injection considerably. They got significant decrease in pain with $20 \mathrm{mg}$ fentanyl on propofol injection is much less than the fentanyl dose that we used, and this discrepancy may be because they mixed propofol with fentanyl and their research done only on female gender ${ }^{19}$.

Ali pour M et al, studied 336 patients compared many drugs and fentanyl to placebo on reducing the pain of propofol injection, the result showed that fentanyl is more significantly reduces pain 
on propofol injection than the other groups ${ }^{20}$. MGupto, S Mishro et al, studied a 100 female patients for evaluation fentanyl, pethidine, dexamethasone compared to placebo group results to decrease the incidence of propofol pain showed that all pretreatment groups the incidence of propofol injection pain reduces considerably more than placebo ${ }^{9}$. Although this study result agrees with our study but still it was used a much lower dose of fentanyl than our dose, this difference may be related to gender (only female) and the patient received diazepam $5 \mathrm{mg}$ on night before surgery.

\section{CONCLUSION}

Pretreatment with either ketamine or fentanyl is an effective method for propofol pain prevention and Ketamine is superior on fentanyl. Furthermore, study on other drugs that may prevent pain during propofol injection.

\section{REFERENCES}

1. D. Singh, S. Jagannath, S.Priye "Prevention of propofol injection pain: Comparison between lidocaine and ramosetron" Journal of Anaesthesiology and Clinical Pharmacol, 30 (2) pp. 213-216, 2014.

2. Witte W, Stein C., "History, Definitions, and Contemporary Viewpoints. In: Kopf A, Patel NB. editors. Guide to Pain Management in Low-Resource Settings. Seattle: International Association for the Study of Pain; 2010, Pages 3-7.

3. Terrence A Leane. "Intravenous fentanyl analgesia with midazolam induced sedation $+/-$ local anesthesia for short painful procedures: a systematic review protocol" JBI Database of Systematic Reviews \& Implementation Reports, 2014;12(8) 38 - 51.

4. E. Liljeroth, Pain induced by propofol, Lund university medical faculty, doctoral dissertation series, 2007.

5. S Ray, R Pal, S Pal, J Kirtania, D Sarbapalli, "Preclusion of pain on injection with propofol: Evaluating the effects of lignocaine or fentanyl pretreatment" Anesth Essays Res 5 pp.3338, 2011.

6. Lamont LA, Mathews KA: Opioids, non-steroidal anti-inflammatories, and analgesic adjuvants. In, Tranquilli WJ, Thurmon JC, Grimm KA (Eds): Lumb\& Jones' Veterinary Anesthesia and Analgesia. $4^{\text {th }}$ ed., pp. 241-271, Blackwell,Iowa, USA, 2007.

7. Barış Kürüm, Zeynep Pekcan, Hakan Kalender, Ali Kumandas, 'Comparison of PropofolRemifentanil and Propofol-Fentanyl Anesthesia During Ovariohysterectomy in Dogs", kvfd. 19 (Suppl-A): A33-A40, 2013 
8. Ben-Shlomo1, ABD-EL-Kalimh, Ezry J, Z Hasr, Tverskomy. Midazolam acts synergistically with fentanyl for induction of anesthesia. British Journal of Anesthesia 1990; 64: 45-7.

9. Ben-Shlomo, J. Finger, E. Bar-AV, A. Z. Perl, A. Etchin And M. Tverskoy, "Propofol and fentanyl act additively for induction of anesthesia" The Association of Anaesthetists of Gt Britain and Ireland, 1993, Volume 48, pages 111 - 113.

10. H. Zahedi, M. Nikooseresht. "Prevention of propofol injection pain with small dose ketamine" M.E.J.ANESTH, 20 (3) pp.401-404, 2009.

11. R. Polat, M. Aktay, O. Özlü. "The effects of remifentanil, lidocaine, metoclopramide, or ketamine pretreatment on propofol injection pain" M.E.J. ANESTH, 21 (5) pp. 673-677, 2012.

12. I Saadawy, E Ertok, A Boker. "Painless injection of propofol: pretreatment with ketamine vs thiopental, meperidine, and lidocaine" Middle East J Anesthesiol, 19 (3) pp.631-44, 2007.

13. S. Koo, S. Cho, Y. Kim, "Small-Dose Ketamine Reduces the Pain of Propofol Injection"Anesth Analg, 103, pp.1444-1447, 2006.

14. F Bano, S Zafar, S Sabbar, S Aftab , S. Haider. ".Intravenous ketamine attenuates injection pain and arterial pressure changes during the induction of anesthesia with propofol: a comparison with Lidocaine" Journal of the College of Physicians and Surgeons-Pakistan , 17(7) pp.390-393, 2007.

15. V. Ayatollahi, S. Behdad, S. Kargar, "Comparison of Effects of Ephedrine, Lidocaine and Ketamine with Placebo on Injection Pain, Hypotension and Bradycardia Due to Propofol Injection: A Randomized Placebo Controlled Clinical Trial " Acta Medica Iranica, 50(9) pp.609-614, 2012

16. L. Jalota, V. Kalira, E. George. "Prevention of pain on injection of propofol: systematic review and meta-analysis" BMJ, pp.342, 2011.

17. MH Nathanson, NM Gajraj, JA Russell. "Prevention of pain on injection of propofol: A comparison of lidocaine with alfentanil" Anesth Analg, 82 pp.469-71, 1996.

18. WW Pang, PY Huang, DP Chang, MH Huang. "The peripheral analgesic effect of Tramadol in reducing propofol injection pain: a comparison with lidocaine" Reg Anesth Pain Med, 24 (3) pp.246-9, 1999.

19. SY King, FM Davis, JE Wells, DJ Murchinson, PJ Pryor. "Lidocaine for the prevention of pain due to injection of propofol" Anesthesia and Analgesia, 74(2) pp. 246-249, 1992. 
20. M. Alipour, Masoomeh Tabari, and Masoomeh Alipour "Paracetamol, Ondasteron, Granisetron, Magnesium Sulfate and Lidocaine and Reduced Propofol Injection Pain" Iran Red Crescent Med, 16(3) 2014.

AJPHR is

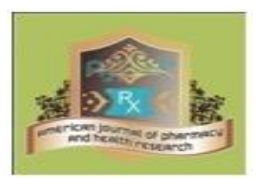

Peer-reviewed

monthly

Rapid publication

Submit your next manuscript at

editor@ajphr.com / editor.ajphr@gmail.com 